RESUMEN Objetivo. Investigar las tendencias y patrones regionales mostrados por la mortalidad por cáncer bucal y faríngeo en el Brasil de 1979 a 2002.

Métodos. La información se obtuvo de la base de datos del Sistema de Informações

La mortalidad por cáncer bucal y faríngeo en el Brasil: tendencias epidemiológicas regionales, 1979-2002

Palabras clave sobre Mortalidade, recopilada por el Ministerio de Salud del Brasil. Las tasas de mortalidad se ajustaron según el sexo y la edad y se aplicó el método de regresión lineal generalizada de Prais-Winsten para calcular el aumento o la reducción anual en las tasas de mortalidad. Las tendencias temporales de la mortalidad por cáncer bucal y cáncer faríngeo se analizaron por sitio anatómico y región del país (norte, noreste, sur, sureste y centrooccidental).

Resultados. Durante el período estudiado, en todas las cinco regiones del Brasil la mortalidad por cáncer bucal se mantuvo estable en ambos sexos, pero la mortalidad por cáncer faríngeo aumentó en los dos. La mortalidad ocasionada por cánceres en los labios, la lengua, las encías, el piso de la boca, el paladar, otras partes de la cavidad bucal y las amígdalas mostró un descenso estadísticamente significativo durante el período examinado. En cambio, la mortalidad por cánceres en la orofaringe, la hipofaringe y puntos mal definidos o indefinidos de la cavidad bucal y la faringe mostró un aumento significativo. Las tasas de mortalidad por cáncer bucal y por cáncer faríngeo fueron más altas en las regiones sur y sureste que en las otras tres regiones del Brasil.

Conclusiones. La reducción más grande que se produjo, en términos relativos, en la mortalidad por cánceres de los labios, encías y otros sitios anatómicos más accesibles a la inspección clínica apunta a un posible vínculo entre la supervivencia de pacientes con cáncer bucal y faríngeo y una mejor provisión de asistencia sanitaria en el Brasil en décadas recientes.

Neoplasias, neoplasias de la boca, neoplasias faríngeas, Brasil.

\title{
ERRATA \\ Rosenfeld $S$ et al. Medication as a risk factor for falls in older women in Brazil. (Rev Panam Salud Publica 2003;13(6):369-375).
}

Two errors appear in Table 2 of the published version (p.372). The 95\% confidence interval $(95 \% \mathrm{Cl})$ of the adjusted odds ratio $(\mathrm{OR})$ for the association between single falls and the use of beta blockers in persons having a body mass index $\leq 30$ should be $0.18-01.41$, rather than $0.18-0.41$. Similarly, the $95 \% \mathrm{Cl}$ of the adjusted OR for the association between single falls and the use of diuretics in persons without musculoskeletal disease should be $0.18-01.37$, rather than $0.18-0.37$. 